\section{INTERVIEW WITH TERRY GLEBOCKI}

INTERVIEW BY ROGER GROS

Roger Gros is the publisher of Global Gaming Business and is based in Las Vegas, Nevada, and Atlantic City, New Jersey.

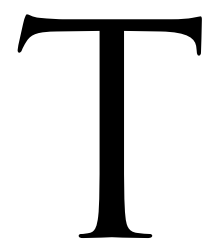

erry Glebocki has a financial pedigree in the gaming industry that goes back 30 years in the business, mostly at the Tropicana. She joined Ocean Casino Resort in July 2019 as CFO and was elevated to CEO in December. As the only leader on the panel who represents a stand-alone casino, Ocean had to fend for itself as it set up procedures and protocols to battle the virus. At the same time Ocean has ample outdoor space to accommodate the dining restrictions, and has been very creative in the use of that space.

ROGER GROS: You have done a great job with your property. Revitalizing the former Revel has been a turning point for Atlantic City. I am really excited about what you have done, and I want to hear about how it has gone since you reopened in early July.

TERRY GLEBOCKI: Hi, Roger. Great to talk to you, and thanks for the kind words. I will say, it is different. Reopening the property was a lot of hard work. It took a lot of planning and preparation, but things are going well. We are learning the protocols, and we are implementing things as we go to make the experience better and better for our guests, and they are taking very well to it.

ROGER GROS: Let's go back to when the shutdown happened. What kind of guidance did you get from the regulators when you got the order to shut down?

TERRY GLEBOCKI: Ocean, along with the other eight properties in town, worked closely with the
DGE [Division of Gaming Enforcement] on closing down, so it was a partnership.

ROGER GROS: Did they have the procedures in place and let you know what had to happen, or did you just close down and then respond to them?

TERRY GLEBOCKI: Every property in town is required to have emergency procedures in the event that they need to shut down for an emergency-a storm or something like that. So those plans were already in place, and we just executed our plan.

ROGER GROS: Sure. Atlantic City casinos had shut down before for other reasons, for storms, legislative problems, and things of that nature.

TERRY GLEBOCKI: Yes, that is correct.

ROGER GROS: You have been developing a great customer base. What was your strategy to stay in touch with them throughout the lockdown?

TERRY GLEBOCKI: We relied heavily on social media. We had postings to stay in touch with both guests and employees. We had thank-you messages out there. We were thanking essential workers. We did a countdown to a reopening date and some "miss you" type videos. Social media was really the best, most effective way to stay in touch with our guests during that time.

ROGER GROS: Obviously, it is important to stay in touch with your employees, as well. They were furloughed early on, and you wanted to make sure that they were ready to go when the reopening showed up. How did you stay in touch with them?

TERRY GLEBOCKI: E-mail was the primary source of communication with the team members. Many of them follow us on social media, as well, so they were watching both of those avenues.

ROGER GROS: How did you prepare for the reopening? Was this something that you put in place and you were just waiting for the okay from the governor?

TERRY GLEBOCKI: We started planning for a reopening the day that we closed. We had to rethink 
our entire business, and we made literally hundreds of operational adjustments to every aspect of the property. We had to put policies in place, and I can't even tell you the amount of signage that we have made to get people aware of the COVID protocols.

We put marketing campaigns in place with what we assumed would be the reopening date, and then it would get pushed, and then we would make a new assumption. We didn't know exactly when we were going to be allowed to open for the longest time.

At the end of the day, the health and well-being of guests, team members, and our community is always a top priority for us. We worked with local health officials, we looked at guidelines from the CDC [Centers for Disease Control and Prevention] and state authorities, and we put together our health and sanitization plan.

ROGER GROS: How much of a curveball was the no-indoor-dining stipulation that Governor Murphy added at the last minute?

TERRY GLEBOCKI: That was very challenging, Roger. We were all ready to open. We thought that we would be able to open with $25 \%$ of our indoor dining space, so we had social distancing measures in place. We had QR codes that were ready. We were going to text people when their tables were ready. We brought back staff. We purchased food. We expected that we were going to have indoor dining, and literally a couple days before we were set to open, that changed.

Keep in mind, if you are familiar with our property, we have no outdoor restaurants. We were trying to come up with a way to service all of our hotel guests. You cannot invite somebody to come stay at your property if you cannot feed them, and you need to be able to feed them for three meal periods. So we had to create new dining options, and it was extremely difficult, but here we are, four weeks later, and we are making it work.

ROGER GROS: You do not have even any restaurants near the outside of the property where you could utilize their kitchens. How do you work that? I understand you have got some dining space out in the parking garage. How do you get the food out there?
TERRY GLEBOCKI: It is challenging, and we needed to be very creative. We do have a lot of outdoor space, but as you say, none of it is adjacent to a kitchen.

We went through the property. We reopened 20 food and beverage outlets so that you can have takeout food, and we immediately put food trucks in our porte-cochère. So we have the takeout options and the outdoor seating areas. We opted to go $24 / 7$ on our room service. If you are staying here as a guest, you are allowed to eat in your room. That was an important amenity. And we added dining to our pools.

Within the next couple weeks, we expect to have an outdoor dining option at our sky garden level. Right now you could take to-go food out there, and you could sit at a picnic table. We are going to have it where guests can go, and they can order from the menu and have food delivered to them there.

Taking care of VIP casino guests was a huge challenge. We do have the Poseidon Pool; it is our adult pool. Every weekend from the beginning we have had a barbecue for invited guests. We do it poolside, and it has been a huge hit.

As you mentioned, our most innovative outdoor dining option was opened this past weekend, and that is our outdoor VIP lounge. It is available to our Black and Chairman cardholders. You can dine outside, rain or shine.

ROGER GROS: That sounds like you really had to get creative.

TERRY GLEBOCKI: We did. Do you know what one of the biggest challenges is? When it rains. When it rains, there is absolutely no place where you can go to eat. So our tagline for the garage is, "When it rains, we have got you covered." Once the governor changed the rules, where you can have a fixed roof as long as two of the outside walls were open air, that is when the garage made sense.

We have got 12 layers, or decks, to our parking garage. We closed off level five. We power-washed it. We cleaned it. There is no vehicular traffic at all on level five. I would love to show you pictures of it. You would never know that you were in a parking garage.

ROGER GROS: That sounds really interesting. 
To say the least, the casino environment is totally unlike it was prior to the shutdown. How have your customers responded to the social distancing, having every other slot machine off, and things of that nature?

TERRY GLEBOCKI: Surprisingly, everyone has adapted pretty well. Our employees and our guests have both given us positive feedback about our protocols. If you look for a silver lining of not reopening right away, people got used to social distancing in New Jersey. They have been going to the essential businesses that were open, so they understood that you are not supposed to stand in line right behind someone else. They knew to wear masks. They had some training before they got here.

ROGER GROS: So you have not had any episodes of people refusing to wear their mask?

TERRY GLEBOCKI: No. A lot of times we have to remind people, "Please cover your nose." Or sometimes they pull it down to take a sip of water and they forget to put it back up. There is some reminding. But for the most part, people have been pretty good.

ROGER GROS: New Jersey seems to be one of the states where the pandemic has subsided a bit. How long do you expect to have to operate under the current stipulations before they start to be relaxed?

TERRY GLEBOCKI: I wish I knew the answer to that. We will continue to operate under these current stipulations and try to find ways to keep getting more creative with our offerings.

We cannot wait until we can get indoor dining back and are able to put all those people back to work. Live entertainment is something that we really miss. But we will do this one step at a time.

ROGER GROS: Now, when entertainment comes back, I imagine it is going to be in the lounges before you can open up the theaters.

TERRY GLEBOCKI: It is going to depend on the guidelines, and we will stay within those guidelines and try to get creative to the best of our ability.

Ovation Hall is an amazing venue, and it creates a great energy in our property when we can have a show there, but we will not do it until it is safe to do so.
ROGER GROS: Unlike some of your other competitors in town, you do not have a corporate entity to lean on when it comes to best practices in this pandemic. How did you develop the systems in use? Did you have to start from scratch?

TERRY GLEBOCKI: Yeah, you are right. Everything we do here at Ocean, it is homegrown. But we started planning for a reopening the day that we closed. One of the things that we do really well here is we listen to our guests. We sent out a survey to over 50,000 of our guests and asked them, "What kind of things are important to you when we reopen?" Safety precautions were very high, as you would expect.

What I was a little surprised by was that loyalty rewards and offers were still very important to them. In addition to hygiene and cleanliness, they still wanted to feel like they were valued. Offers mattered more now than ever before, and we have continued to deliver really good comps and rewards to our guests.

ROGER GROS: Your fantastic hotel rooms are a big draw, as well, since you can certainly social distance there, and there are great views and everything that you offer there, particularly now that you have the in-room dining, as well.

TERRY GLEBOCKI: Yes, our rooms have been very popular. Even before, when this was under prior ownership, people loved the views that they could get there, and our hotel has been filling up every weekend - or every day, really. We will be in the high $90 \%$ occupancy range, high 90 s, this month.

ROGER GROS: It is really encouraging to hear that people are interested in coming back to that great extent.

TERRY GLEBOCKI: Absolutely.

ROGER GROS: The state has passed a couple of bills that give you some tax relief for the problems you encountered during the lockdown. Will that be enough to tide you over?

TERRY GLEBOCKI: The state has not passed the bills yet. There are bills that are pending in the legislature, and they would be very much welcomed and appreciated if they do pass. But that has not happened yet. 
We are encouraged by the results since the reopening. Not only Ocean, but the entire industry needs to overcome that period that we were shut down. It costs millions of dollars a month to keep these properties open. When there is no revenue, that creates quite a hole that needs to be filled. We are very, very hopeful that these bills pass.

ROGER GROS: What do you think is going to draw more people to Atlantic City once this starts to die down? Is there something that Atlantic City needs to do to bring more people back?

TERRY GLEBOCKI: I have been preaching this one for a while. Atlantic City needs to focus on and promote all of the positive things that we have. We have got some beautiful offerings here. We have got the beach, we have got the boardwalk. Obviously, we have got gaming, the resorts, dining. There is so much variety here. As the properties continue to invest in and improve the product, if we can all work together and positively promote Atlantic City, that will be critical.

A really good example of that is North Beach. Here at Ocean, we are part of the North Beach community, and we work together with the two other casinos in this area and a lot of the non-gaming amenities in this North Beach part of town, and we promote North Beach as a community, and it has been fabulous.

ROGER GROS: During this pandemic, have you been having more discussions with the other leaders of the properties in town? Is there a lot of back and forth and "How are we going to do this?"

TERRY GLEBOCKI: There is a lot. The Casino Association typically meets once a month. During the pandemic, there were times when we were meeting twice a day. It is a great group to work with, and everyone was working together and putting the best ideas forward, and it is a nice group to be associated with.
ROGER GROS: That is good to hear. That bodes well for the future, I would imagine.

TERRY GLEBOCKI: Absolutely.

ROGER GROS: Meetings and events have always been a big part of the Atlantic City business, and you have got some great meeting space at Ocean. When do you think that is going to come back?

TERRY GLEBOCKI: I have no idea when large indoor gatherings are going to be allowed. We are already doing some smaller groups, and we do have people that have expressed interest. We explain to them, "Here is what we are allowed to do based upon the protocols that are put in place by the state." In the meantime, we are making sure that guests feel safe, and they have a good time while they are here.

ROGER GROS: Ocean is owned by a hedge fund, and that usually means it is up for sale at the right price. How does that impact the operations at Ocean?

TERRY GLEBOCKI: It is probably different than you would expect. Being owned by a hedge fund is probably the biggest advantage we have because we are a standalone asset, and it gives us an opportunity to cater our operations here at Ocean specifically to the AC market and the AC customer, whereas some of the other properties in town, they are part of giant national brands that dictate a lot of their strategies and their protocols. But Luxor, who is our owner, gives us flexibility. We are nimble. We can react quickly and make decisions that are prudent to our specific operation.

There was a plenary license hearing a few months ago. There, Ocean said that this is a long-term holding for them. And I can tell you, I am really proud of the results that we have had here, and I know that they are exceptionally pleased with the momentum we had both before the closing and since our reopening. 